\title{
Del des-contexto al descontento: agenda y discurso de la prensa durante las elecciones autonómicas en la Región de Murcia (2011)
}

\author{
Enrique ARROYAS LANGA \\ Universidad Católica San Antonio de Murcia \\ earroyas@ucam.edu \\ Pedro Luis PÉREZ DIAZ \\ Universidad Católica San Antonio de Murcia \\ plperez@ucam.edu \\ Celia Berná Sicilia \\ Universidad Católica San Antonio de Murcia \\ cberna@ucam.edu
}

Recibido: 03/07/2012

Aceptado: 16/10/2012

\begin{abstract}
Resumen
Este artículo estudia la mediación de la prensa en la fijación de la agenda temática durante la campaña electoral de las elecciones autonómicas de la Región de Murcia en 2011. En el marco de la teoría de los géneros periodísticos, se analizan las noticias de portada y las informaciones de la campaña en los dos periódicos regionales (La Opinión y La Verdad de Murcia), en busca de indicadores que definan la cobertura periodística de estos medios. El análisis revela que los medios trasladaron a la ciudadanía las propuestas de los candidatos, pero silenciaron los temas que más preocupaban a los ciudadanos según los sondeos. Además, la escasez de piezas del género interpretativo que aportaran contexto y enriquecieran el debate con temas alternativos y surgidos de la iniciativa periodística pone de manifiesto que la cobertura de la campaña electoral realizada por estos diarios no contribuyó a paliar el descontento que la sociedad civil ha expresado a través de movimientos como el 15M.
\end{abstract}

Palabras clave: agenda temática, discurso periodístico, géneros, mediación, campaña electoral.

\section{From decontextualization to disaffection: agenda and discourse of the press during the autonomic elections in the Region of Murcia (2011)}

\begin{abstract}
This paper reports on the mediation of the press and the agenda-setting during the 2011 autonomic elections campaign held in the Region of Murcia (Spain). From the classical theory of journalistic genres, we apply content analysis to every single news story related to the campaign published on the front page and the inside pages of two regional newspapers (La Opinión and La Verdad of Murcia), looking for indicators that define the coverage of both media outlets. Our analysis reveals that media simply transferred the proposals from the candidates to the readers, but silenced the issues of greatest concern to citizens, according to polls. In addition, the lack of interpretive genre stories, that would have add context and enriched the debate with alternative issues emerged from the journalist's initiative, shows that the news coverage of the election campaign by these newspapers didn't help to alleviate the discontent that civil society has expressed through movements like $15 \mathrm{M}$.
\end{abstract}

Keywords: agenda-setting, journalistic discourse, journalistic genres, mediation, electoral campaign.

\section{Referencia normalizada}

ARROYAS LANGA, Enrique; PÉREZ DÍAZ, Pedro Luis y BERNÁ SICILIA, Celia (2012): "Del descontexto al descontento: agenda y discurso de la prensa durante las elecciones autonómicas en la Región de Murcia (2011)". Estudios sobre el mensaje periodístico. Vol. 18, núm. especial octubre, págs.: 87-99. Madrid, Servicio de Publicaciones de la Universidad Complutense. 
Sumario: 1. Introducción. 2. La importancia del contexto en la información política. 3. Estrategias de control de la agenda temática. 4. Metodología. 5. Análisis y resultados; 5.1. Análisis cualitativo: revisión de los titulares de las portadas referidos a la campaña autonómica; 5.2. Análisis cuantitativo: revisión de las piezas informativas de la campaña autonómica. 6. Conclusiones; 6.1. Una agenda temática desconectada de la ciudadanía; 6.2. Una mediación periodística descontextualizada; 6.3. Una cobertura dominada por el discurso político. 7. Referencias bibliográficas.

\section{Introducción}

Este trabajo trata de determinar, desde el marco de las teorías de la mediación, qué mecanismos operaron en la selección de temas que articularon la agenda informativa de la campaña de las elecciones autonómicas de mayo de 2011 en la Región de Murcia. Con el análisis de la cobertura efectuada por los periódicos regionales, se buscan indicadores que permitan dilucidar qué actor llevó la iniciativa en el control de la agenda.

La acción mediadora que llevan a cabo los medios de comunicación -especialmente los periódicos- desempeña un papel crucial en el proceso de tematización al orientar la atención del público hacia los temas más destacados. En periodo electoral, esta tarea de mediación es si cabe más intensa y decisiva, pues los agentes políticos mantienen un pulso directo con los medios por la definición de los asuntos públicos que centrarán los discursos de campaña.

Los datos obtenidos en el análisis realizado confirman nuestra hipótesis inicial de que los medios impresos de la Región de Murcia cedieron en gran medida el control de la agenda temática a los líderes políticos en las elecciones autonómicas de 2011, renunciando, con ello, al cumplimiento de uno de sus deberes esenciales: trasladar a la esfera pública las inquietudes de la ciudadanía e interpelar a los políticos acerca de los problemas sociales.

Tal y como se muestra en este estudio, algunos de los asuntos que, según las encuestas y otros cauces del debate político (redes sociales y cibermedios), en aquel momento preocupaban a la ciudadanía -como el $15 \mathrm{M}$ o la corrupción política-quedaron al margen del debate público.

Para desarrollar esta investigación se ha empleado la metodología del análisis de contenido, consistente en el pormenorizado estudio de las piezas informativas publicadas durante los 15 días de campaña en las páginas de los dos diarios de mayor tirada de la comunidad autónoma: La Verdad y La Opinión.

\section{La importancia del contexto en la información política}

Por su posición central en el espacio público, los medios periodísticos tienen un papel relevante en el establecimiento de los esquemas explicativos que se aplican a los acontecimientos. Este enfoque interpretativo del periodismo eleva la función del periodista por encima de la simple labor de intermediación entre el emisor y el destinatario del mensaje al apelar a su capacidad creativa para exponer a los ciudadanos los argumentos necesarios para que puedan entender la realidad.

La clave interpretativa que aporta significación a las noticias es de carácter contextual en el periodismo, pues es en relación con el contexto como se seleccionan, valoran y ordenan los elementos de una información. De la capacitación contextual del periodista y de su esfuerzo por construir marcos cognitivos de interpretación dependerá que surja una cobertura periodística de los temas que ofrezca al ciudadano una información con 
sentido. Si la noticia no se proyecta en un contexto significativo, la información "queda mutilada, permanece muda: [...] no hay texto sin contexto" (Burguet, 2008: 265).

La interpretación periodística de la realidad se expresa a través de una gama de modalidades discursivas que son los géneros periodísticos, con los que se recoge, con diferente propósito, la complejidad de lo que acontece. Una noticia ofrecerá una interpretación inicial que dará al receptor una primera idea sobre su relevancia. En un segundo nivel, un reportaje intentará profundizar en la interpretación de modo que se ayude al público a valorar los hechos (Gomis, 1991). Solo con la acumulación de mensajes informativos e interpretativos de distintos géneros (noticias, reportajes, entrevistas, crónicas) se pueden encontrar los elementos explicativos necesarios para la comprensión de los hechos: relaciones de contexto, antecedentes y posibles consecuencias. De la solidez de este recorrido interpretativo dependerá que el periodismo cumpla con la función social que le da sentido: ayudar a "comprender nuestro mundo y el lugar que ocupamos en él” (Kovach y Rosenstiel, 2003: 264).

Además, los géneros interpretativos adquieren mayor importancia en casos polémicos, de interés público y ante conflictos y, por lo tanto, en la información política. En las campañas electorales, disponer de una buena información sobre los hechos facilitará al ciudadano la intervención en el debate público. Por ello, la función mediadora del periodismo es un factor que condiciona la participación de los ciudadanos en la vida pública. Además de su capacidad de hacer comprensibles los asuntos complejos de la actualidad, la utilización de estos géneros otorga a un medio periodístico originalidad e independencia, dos cualidades que fortalecen su posición como mediadores y que son muy valiosas en el contexto de la información política, cuya vinculación con la propaganda provoca a menudo el desinterés del público.

La realización de reportajes y entrevistas por iniciativa del medio, al margen de las convocatorias oficiales y demás actos de campaña, permitiría al medio que las publica diferenciar su oferta informativa, ofrecer una agenda de temas desvinculada de los intereses de los partidos y buscar perspectivas novedosas a partir de fuentes propias. De esta forma, la utilización de géneros interpretativos aleja al periodismo de un modelo de cobertura controlado por la esfera política.

Sin embargo, esta investigación demuestra que los periódicos centraron sus mensajes en la información de los hechos, pero de forma fragmentaria, aislada de su contexto. La escasez de reportajes, entrevistas y crónicas contribuyó a la uniformización de la cobertura periodística de campaña y fue un factor que condicionó el control de la agenda, de modo que los temas elegidos correspondieron a la agenda establecida por los partidos políticos, sin que los periódicos aportaran temas y discursos alternativos.

\section{Estrategias de control de la agenda temática}

Además de su escasa contextualización, la cobertura periodística de la campaña adoleció de falta de sintonía con los intereses de los ciudadanos, según se desprende del análisis de la presencia que tuvieron en la prensa de la Región de Murcia algunos de los temas que preocupaban a la ciudadanía.

De acuerdo con los estudios sociológicos que en aquel momento pulsaron la opinión pública, la cobertura periodística se realizó en un clima de desafección política que cristalizaría en las manifestaciones surgidas al amparo del movimiento $15 \mathrm{M}$. 
Los datos del informe presentado por el Centro de Estudios Murcianos de Opinión Pública (CEMOP, 2011) en mayo de 2011 corroboraron que los murcianos valoraban mayoritariamente la situación política de la Región de Murcia como mala/muy mala $(40,1 \%)$ o como regular (36,5\%). La valoración de la gestión del Gobierno autonómico del Partido Popular (PP) fue calificada, asimismo, como mala o muy mala por parte del $28,4 \%$ y como regular por parte del $31,5 \%$, lo que significaba que uno de cada dos murcianos se sentía insatisfecho con las acciones del Ejecutivo regional.

La actuación del PSOE fue igualmente valorada de forma negativa por los ciudadanos. En concreto, un $52,3 \%$ la estimaron mala o muy mala y un $28,6 \%$, regular. También los datos sobre el grado de implicación y compromiso de los murcianos a la hora de votar evidenciaron cierto descreimiento.

En el ámbito nacional, los datos del barómetro del CIS de mayo y junio confirmaron que cuestiones como la corrupción política o el funcionamiento de las instituciones democráticas estaban en el centro de las preocupaciones de la calle (2011a; 2011b). Además, en estos dos meses, la clase política y los partidos se situaron como el tercer problema para los españoles (mayo: $22,1 \%$; junio: $24,7 \%$ ), solo por detrás del paro y los problemas de índole económica.

Si las encuestas nos permiten conocer los estados de opinión del público acerca de los problemas de una comunidad, el escenario mediático desempeña una función señalizadora acerca de la importancia que tienen los asuntos de interés público. Por eso, la composición de la agenda de temas políticos durante el periodo de campaña concentra buena parte de los esfuerzos de la comunicación de los partidos políticos. Los actores políticos intentan que los temas que se seleccionen sean aquellos que favorezcan sus intereses y que los acontecimientos planificados por sus fuentes pasen a formar parte de la agenda pública a través de la creación de eventos con estrategias de marketing político (mítines, inauguraciones, cumbres o fiestas), lo que permite al político difundir sus propuestas y obtener notoriedad (Maarek, 1997; Casero, 2009).

Junto a la disputa por la selección de temas en el debate político, el control de la agenda mediática también depende del tipo de cobertura informativa que desarrollen los medios. El predominio del periodismo de declaraciones, es decir, de informaciones sobre reacciones y valoraciones por parte de sujetos políticos, es el síntoma de una selección temática en la que el estatus de la fuente informativa ha prevalecido sobre el interés de los hechos o los temas de fondo. La inflación de declaraciones, notas de prensa y comunicados, ante la pasividad de un periodismo incapaz de diferenciar la propaganda de la información, es otra forma de control de la agenda por parte de los partidos, que da como resultado una información política simplificada, basada en estereotipos y fuertemente polarizada, sobre todo en periodo de campaña electoral.

Esta última tendencia es considerada como una de las causas del desprestigio actual de la política y, de forma paralela, de la pérdida de credibilidad de los medios periodísticos, que son percibidos por la ciudadanía como simples vehículos de expresión de estrategias políticas más que como agentes activos de la dinámica social y la vida de la colectividad. 
Frente a estas estrategias del poder, los géneros periodísticos sirven a los medios como herramientas para contrarrestar el control político de la agenda enriqueciendo el debate y reforzando su labor interpretativa.

\section{Metodología}

Tradicionalmente, se ha afirmado que las portadas de la prensa son como una "vitrina" o "escaparate" donde se exhiben los mejores contenidos, como una síntesis meditada de lo que el medio ofrece a sus lectores: "A esta página van a parar no solo las noticias más importantes del día, sino aquellas que los responsables del periódico quieren destacar por muy diferentes motivos" (Berrocal y Rodríguez, 1998: 66). Dada su naturaleza heurística, nos pareció adecuado abordar las portadas de la muestra estudiada de forma exploratoria, con objeto de consolidar nuestra hipótesis o encontrar potenciales enfoques que completaran el posterior análisis cuantitativo.

Para ello, se empleó un análisis de contenido cualitativo que nos ayudase a interpretar las piezas recolectadas -las portadas-a partir de algunas categorías analíticas a priori. Estas alumbraron nuestro estudio antes de desarrollar el análisis cuantitativo que reduce "el material estudiado a las categorías analíticas a partir de las cuales se puede producir las distribuciones de frecuencia, los estudios de correlación, etc." (Landry, 1993: 412). Recurrimos a ambas aproximaciones bajo la premisa de que prestar atención a las "particularidades de la subjetividad" puede ser útil para complementar la supresión del sesgo subjetivo de las metodologías cuantitativas.

El análisis cualitativo consistió en la observación no estructurada de las portadas de los diarios estudiados, La Verdad y La Opinión de Murcia, durante los días de campaña (del 6 al 22 mayo de 2011), prestando atención a aquellos titulares de portada relativos a la información contenida en páginas interiores sobre los comicios autonómicos. En todo momento, se buscó realizar un análisis indirecto que fuera más allá del contenido textual manifiesto para profundizar en su sentido latente, buscando asociaciones entre las categorías de nuestra hipótesis: temas, géneros, enfoques, tipo de cobertura de información política...

Tras esta auscultación cualitativa, se procedió a la recopilación sistemática de las informaciones vinculadas con la campaña en el interior de ambos periódicos. Las conclusiones que arroja el análisis derivan del exhaustivo examen de todos los textos recopilados.

El periodo de investigación se dividió en tres etapas con objeto de observar la evolución de los temas de campaña, teniendo en cuenta que hubo dos sucesos inesperados -terremotos de Lorca y movimiento $15 \mathrm{M}$ - que pudieron tener influencia en el debate. La primera abarca desde el arranque de la campaña al día en que se produjeron los seísmos (6-11 de mayo); la segunda engloba los días en los que esta catástrofe natural se situó en el centro del foco político y mediático (12-17 de mayo); y la tercera se corresponde a la recta final de la pugna electoral, en la cual irrumpió el movimiento $15 \mathrm{M}$ (18-22 de mayo).

En virtud de la naturaleza y los objetivos de la investigación, se diseñó una hoja de codificación que fue aplicada a los distintos textos objeto de estudio. Esta plantilla constaba de 40 preguntas, divididas en cuatro grandes bloques (identificación ge- 
neral de la unidad de análisis, aspectos formales, aspectos específicos del contenido gráfico, aspectos específicos del contenido textual) y articuladas en torno a tres ejes: temático (temas que protagonizaron la campaña electoral), evaluativo (modo de presentación de los enfoques y atributos y su vinculación con los actores de la campaña) y cronológico (evolución de las categorías y coincidencias con motivos significativos del proceso electoral).

Al elaborar este cuestionario, se hizo especial hincapié en la determinación de cuáles fueron los temas protagonistas en la escena política y mediática. Debido a la amplia heterogeneidad de los temas abordados durante la campaña electoral de 2011, y con objeto presentar los datos de manera más clara y comprensible, los asuntos que tuvieron cabida en el debate mediático en las elecciones se agruparon en distintas macrocategorías.

Para verificar nuestra hipótesis, la plantilla contempló, además, toda suerte de aspectos relacionados con el tratamiento informativo de los temas de campaña: tipo de texto (géneros periodísticos empleados en la cobertura), extensión, sujetos protagónicos y otros datos vinculados con la cultura profesional y las rutinas del periodista (entorno en el que se gesta la noticia).

En total, la muestra estudiada ascendió a un total de 211 unidades de análisis relacionadas con la campaña electoral autonómica y provenientes de las dos cabeceras de mayor tirada y difusión en la Región de Murcia. Una vez recabados los datos, se procedió al tratamiento estadístico de los mismos empleando el programa SPSS (versión 20).

\section{Análisis y resultados}

A continuación, efectuamos un exhaustivo repaso por los datos más significativos que arroja el análisis cualitativo y cuantitavo en relación con nuestra hipótesis inicial: la falta de profundidad e iniciativa de la prensa en la cobertura y la escasa presencia de temas cercanos a los problemas expresados por la ciudadanía en las encuestas. Focalizaremos, por ello, gran parte de la atención en los temas que integraron la agenda mediática y en el tipo de géneros empleados.

\subsection{Análisis cualitativo: revisión de los titulares de las portadas referidos a la campaña autonómica}

Las conclusiones más destacadas que se derivan del análisis cualitativo de los titulares de portada son:

- Las portadas de ambos periódicos se centraron en presentar la campaña exaltando el carácter competitivo de los grandes partidos, como si de una contienda se tratase (horse-race coverage) (Patterson, 1980).

- Más escasas fueron las noticias en portada centradas en los temas de campaña (issues coverage). Solo en los primeros días La Verdad abordó asuntos como el empleo, la Ley de Dependencia o el compromiso de la candidata García Retegui de no gobernar más de 8 años en caso de que su formación venciese en los comicios. Este tipo de coberturas temáticas pueden materializarse de dos 
modos, según se establecen los temas: de un lado, las coberturas que explican las propuestas de los partidos políticos; de otro, las que establecen de forma autónoma cuáles son los asuntos públicos más relevantes para la campaña, al margen de los programas de los partidos. En las primeras, los periodistas siguen la agenda de los políticos para explicar sus programas mientras que en las segundas los periodistas establecen su propia agenda según las necesidades de los ciudadanos (McCombs, 2004). La mayoría de las noticias de portada respondían a este primer modelo.

- La citada tendencia puede corroborarse también a la vista de las numerosas coberturas de declaraciones (Bennet, 1996), habida cuenta de que los titulares recogían de forma directa o indirecta las afirmaciones de los líderes políticos ${ }^{1}$. El cruce de acusaciones y refriegas pareció contribuir a la percepción sostenida de asistir a una campaña de discursos vacíos de ideas ${ }^{2}$.

- De forma paralela, o quizá como consecuencia de lo anterior, el criterio editorial de ambos diarios privilegió la presencia de sondeos en sus portadas. El reduccionismo positivista de las encuestas, que identifica la opinión pública con un agregado de respuestas individuales, se convirtió en una rémora que dejó poco espacio para el debate político. Las encuestas del CIS, el CEMOP e Ikerfel ${ }^{3}$ se fueron dosificando hasta apurar el plazo establecido por la legislación electoral española, según la cual no se pueden publicar sondeos electorales durante los cinco días anteriores al de la votación.

- Entre los días 10 y 12 de mayo, y en consonancia con la suspensión de la campaña a causa de los terremotos de Lorca, ninguna portada trató las elecciones. A raíz de este evento, la participación en el proceso electoral fue otro tema visible, especialmente en alusión a cómo la catástrofe de Lorca podía estar afectando al proceso electoral $1^{4}$.

- En las portadas de ambas cabeceras, la irrupción en campaña del movimiento $15 \mathrm{M}$ fue abordada desde el 16 de mayo casi exclusivamente desde la perspec-

1 “González Pons dice en Murcia que recuperarán el Ministerio de Agricultura" (La Opinión (10/05/11); "Valcárcel deja entrever que Juan Bernal entrará en su Gobierno" (La Opinión, 11/05/11); "Pujante: 'Paramount es un cuento en el que Valcárcel acabará trabajando de Donald"' (La Opinión 18/05/11).

2 En la portada de La Opinión del 11/05/11 se destacaban las palabras del jefe de Opinión del diario, Ángel Montiel, quien señalaba que se estaba desarrollando una campaña sin ideas, pero sin indicar claramente a los culpables de ese escenario: "Si se fijan, en estas elecciones no se habla de programas, ni siquiera hay eso que se denomina "ideas-fuerza"".

3 "El CIS otorga al PP un aumento de la mayoría absoluta en la Asamblea" (La Opinión, 06/05/11); "El PP ganará en la Región con más del doble de votos que el PSOE” (La Verdad, 08/05/11); "El PP superaría en 6 diputados la mayoría absoluta" (La Opinión, 15/05/11); "Cuatro de cada cinco murcianos dan por hecho que ganará el PP" (La Opinión, 16/05/11).

4 "La campaña encara la recta final sin pulso" ( La Verdad, 16/05/11); "La caída del voto por correo alienta el fantasma de la abstención” (La Opinión, 17/05/11). 
tiva del conflicto, presentándolo como un pulso a las autoridades ${ }^{5}$. Ninguna información trató de dilucidar las ideas motrices que impulsaban las protestas de este segmento de la ciudadanía para incluirlas en el debate. Los titulares solo daban cuenta del desafío al orden público y apenas aludieron a las cuestiones de fondo ${ }^{6}$, al igual que sucedió cuando los líderes políticos hicieron referencia al asunto ${ }^{7}$.

\subsection{Análisis cuantitativo: revisión de las piezas informativas de la campaña au- tonómica}

El examen de las piezas informativas analizadas cuantitativamente revela que la campaña protagonizada por Valcárcel (PP), García Retegui (PSOE) y Pujante (IU) estuvo centrada esencialmente en tres ámbitos: la crisis económica, los líderes políticos y los datos de encuestas. En este sentido, es reseñable que los candidatos autonómicos no aparecieron en informaciones cuyo tema principal se identificara con el $15 \mathrm{M}$, lo que revela que el debate generado por esta movilización popular no fue integrado en el discurso de los políticos.

El protagonismo alcanzado por los agentes políticos (20\%), la crisis económica (18\%) y los datos demoscópicos del desarrollo de la campaña $(15,1 \%)$ en la agenda de los periódicos regionales contrasta con la poca relevancia que obtuvieron otras cuestiones que, según hemos visto en las encuestas de opinión efectuadas en el momento electoral, preocupaban a la ciudadanía. Así, asuntos como la corrupción política o los temas de fondo del movimiento $15 \mathrm{M}$ quedaron prácticamente al margen de la discusión mediática con índices de frecuencia de aparición del 3,4\% y del 5,6\%, respectivamente . $^{8}$

5 "Miles de 'indignados' desafían la prohibición y colapsan la Puerta del Sol" (La Opinión, 19/05/11); "Miles de 'indignados' desafían la prohibición y toman la Puerta del Sol" ( $L a$ Verdad, 19/05/11); "La Junta Electoral central prohíbe concentraciones y manifestaciones en sábado y domingo" (La Opinión, 20/05/11).

${ }^{6}$ Como un ejemplo de la superficialidad de la cobertura sobre el $15 \mathrm{M}$, se puede destacar que el único titular de portada que no trataba el movimiento como una afrenta al orden pertenecía a un reportaje que se limitaba a recopilar las consignas empleadas por los "indignados", lo que da una idea de hasta qué punto la frivolidad de las formas acabó por someter a las cuestiones de fondo: "Los lemas del movimiento que ha irrumpido en plena campaña electoral" (La Verdad, 20/05/11).

${ }^{7}$ La Verdad destacó las declaraciones del entonces secretario general del PP, Mariano Rajoy, en las que defendía la integridad de los representantes públicos: "Rajoy replica en Murcia a 'Democracia Real' con una defensa de los políticos" (La Verdad, 18/05/11).

${ }^{8}$ Resulta interesante comparar estos datos con los obtenidos en un estudio similar de los anteriores comicios elaborado por el Grupo de Investigación en Comunicación Política e Imagen de la UCAM (Zamora, 2009). Se observa que la agenda temática de la campaña en 2011 fue muy diferente a la de 2007, ya que desaparecen del debate temas como la corrupción política y el conflicto del agua, que estuvieron muy presentes en las elecciones anteriores. 
Por otro lado, tampoco se observa una evolución de los temas durante los tres periodos en los que dividimos la campaña (inicio, ecuador, recta final). Los resultados evidencian que no se produjo un giro significativo, como quizá cabría esperar a la luz de los acontecimientos que se desarrollaron tras el 15M. Así, en la última etapa, solo se habló más sobre Infraestructuras y Datos de encuestas electorales ${ }^{9}$, mientras que otras cuestiones candentes que se encontraban presentes, según hemos visto, en el centro del debate ciudadano, como la corrupción y la crispación política, apenas tuvieron eco durante los últimos días de la contienda electoral. En este sentido, se puede afirmar que los líderes políticos desoyeron a la ciudadanía y la prensa faltó a sus responsabilidades al no tratar adecuadamente sus preocupaciones ni servir como foro de intercambio entre representantes y representados ${ }^{10}$.

Figura 1. Frecuencias de los temas abordados. Fuente: elaboración propia.

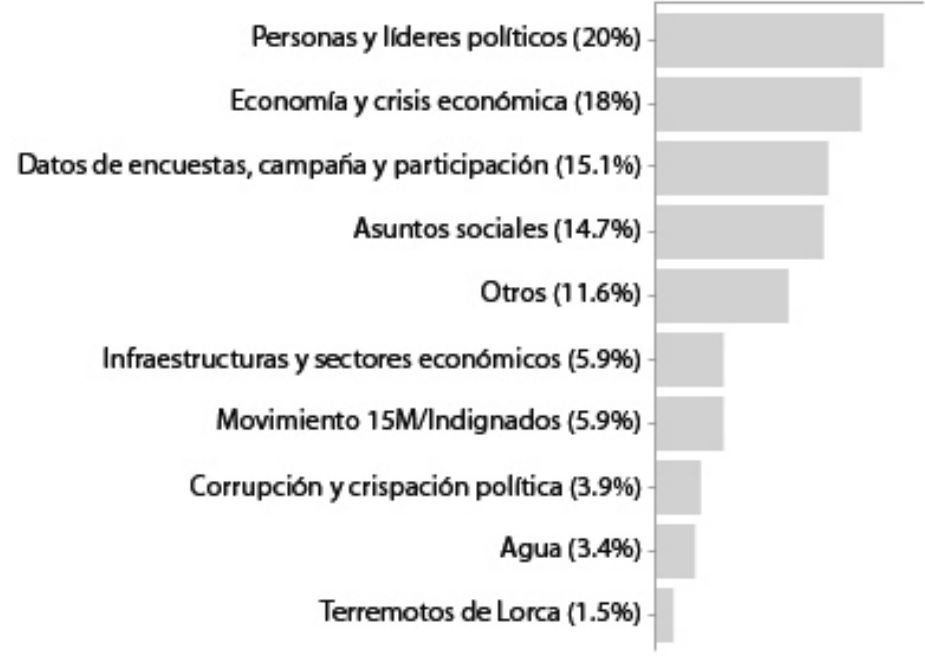

En lo que se refiere a los géneros periodísticos que dieron forma a la cobertura de la campaña electoral de 2011, hemos de indicar que predominó el género de noticia (la mitad de unidades analizadas), en detrimento de los géneros interpretativos (reportajes, entrevistas, análisis, etc.). Solo un $6,2 \%$ de piezas se vinculan con este tipo de informaciones más elaboradas y que parten de la iniciativa del periodista, lo que ofrece un indicador sobre el control de la agenda temática.

9 Sobre el tema $15 \mathrm{M}$ también se habló más en este periodo, aunque el dato no resulta relevante porque anteriormente este asunto no existía como tal.

10 Los ciudadanos encontraron otras vías para canalizar sus inquietudes: las redes sociales y la sección de comentarios de los periódicos regionales. Pérez Díaz, Noguera y Grandío (2012), en un estudio sobre la conversación ciudadana que tuvo lugar durante aquellos días en las redes sociales, determinaron que la agenda ciudadana en Twitter se mostró divergente a la de los medios. Arroyo y Arroyas (2012), por su parte, en su aproximación a los comentarios elaborados por los lectores en las ediciones digitales de los dos diarios de la Región, observaron que la aparición en escena de los "indignados" enriqueció el debate. 
Figura 2. Frecuencias de los géneros empleados. Fuente: elaboración propia.

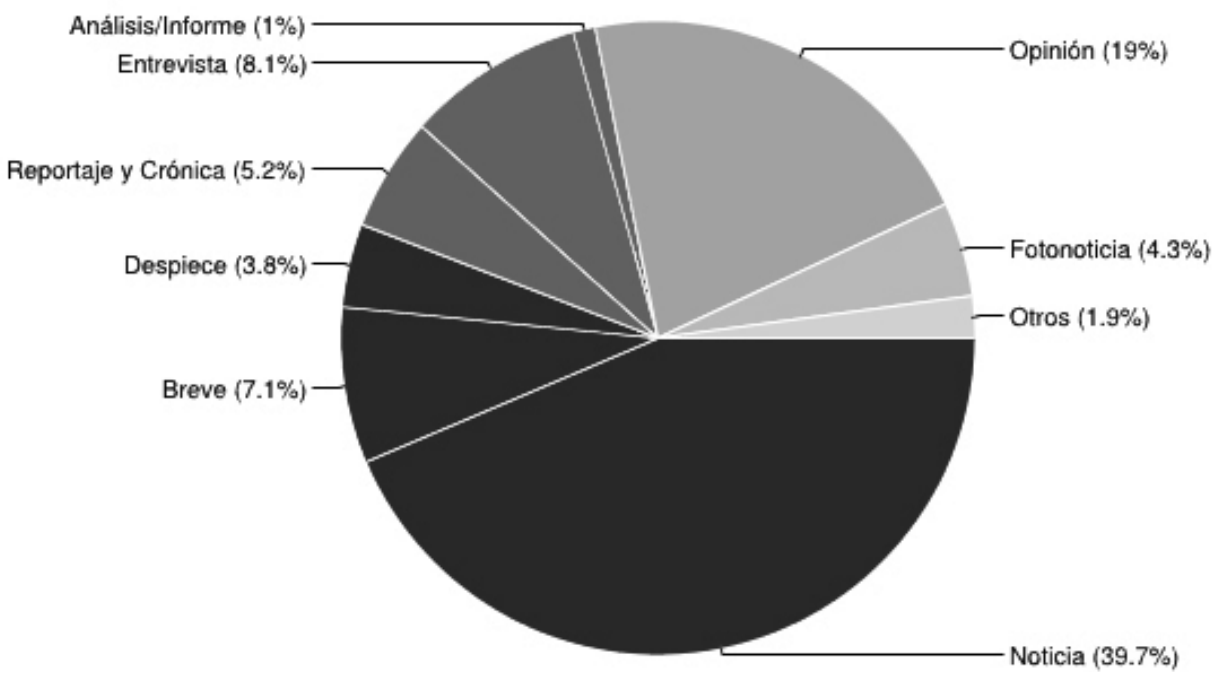

Al relacionar los temas tratados con el género periodístico empleado, dentro del género seco, destacaron las noticias relacionadas con los líderes políticos, los datos de encuestas y campaña y el empleo. Significativamente, las entrevistas en las que el periodista plantea las preguntas sí se centraron, de entre todos los temas recogidos, en aquellos que en aquel momento preocupaban a la ciudadanía: la crisis $(35,3 \%)$ y el empleo $(17,6 \%)$.

Los políticos murcianos prepararon estratégicamente una campaña electoral basada en actos planificados, lo que influyó en el entorno controlado al que los periodistas acudían para recoger la información. Los actos sectoriales y las declaraciones constituyeron el marco principal del que surgió más de la cuarta parte de textos $(26,8 \%)$, mientras que los mítines y los encuentros con votantes originaron el 12,8\% de las informaciones. Los textos de género seco se articularon en torno a actos planificados por los partidos políticos y, especialmente, las noticias, dado que un $60,9 \%$ de estas piezas se originó en un mitin, una rueda de prensa o a partir declaraciones producidas en convocatorias.

\section{Conclusiones}

Los resultados ofrecidos corroboran que los medios trasladaron a la ciudadanía las propuestas de los candidatos, pero silenciaron los temas que más preocupaban a los ciudadanos según los sondeos. La cobertura de la campaña electoral realizada por los dos principales periódicos de la Región de Murcia no ayudó a estrechar la distancia entre los políticos y la ciudadanía.

\subsection{Una agenda temática desconectada de la ciudadanía}

Tres temas acapararon la cobertura electoral de la prensa: la crisis económica, los líderes políticos y los datos de encuestas. La escasa presencia de informaciones sobre 
el $15 \mathrm{M}$ revela que el debate generado por esta protesta ciudadana no fue integrado en el discurso de los políticos ni recibió la atención de los medios.

El protagonismo alcanzado por los temas relacionados con la pura estrategia electoral contrasta con la poca relevancia de los asuntos que preocupaban a la ciudadanía. Las quejas ciudadanas sobre la corrupción política y las denuncias por el deterioro del funcionamiento de la democracia quedaron fuera de la cobertura mediática. De hecho, se podría argumentar que el movimiento $15 \mathrm{M}$ no fue tratado por ninguno de los periódicos como un tema político.

La irrupción de este suceso inesperado apenas alteró la agenda política ni la agenda de los medios, lo que apunta a que la prensa aceptó las estrategias de los políticos sobre aquello que merecía formar parte de la discusión pública, poniendo de manifiesto la desconexión con las preocupaciones expresadas en la calle.

La realidad de la mediación analizada en este estudio pone de relieve no solo que la opinión publicada era muy diferente de la opinión pública, sino también que el discurso de la prensa coincidió con el discurso de la clase política. De esta forma, los datos obtenidos confirman nuestra hipótesis de que la prensa desempeñó de forma deficiente su tarea de mediación, al no trasladar al debate político las preocupaciones reales de la ciudadanía.

\section{2. Una mediación periodística descontextualizada}

La mediación periodística fue también deficiente por su pasividad y falta de esfuerzo contextualizador de la realidad política. El género periodístico más utilizado en la cobertura de la campaña fue la noticia, en detrimento de los reportajes, las entrevistas, las crónicas y los análisis, géneros que, al surgir de la iniciativa del periodista, hubieran permitido marcar distancias con respecto a la estrategia política, proporcionando al público una explicación de los asuntos políticos, un contexto.

Del mismo modo, la superficialidad mostrada en los titulares de portada de La Opinión y de La Verdad, con textos centrados casi única y exclusivamente en la lucha de poder (la campaña electoral como 'carrera de caballos') o en informaciones de agenda de campaña, así como la abundancia de noticias de declaraciones arroja luz sobre cuál fue el papel que desempeñó la prensa y sobre cómo fueron los intercambios que esta articuló con el poder político en este periodo.

\section{3. Una cobertura dominada por el discurso político}

Los medios periodísticos no disputaron el control de la agenda temática, sino que la dejaron en manos de los líderes políticos sin ofrecer un discurso alternativo al poder. La cobertura de la campaña descansó en el seguimiento de los actos planificados por los estrategas de los partidos. Es decir, las informaciones periodísticas se limitaron a dar visibilidad a los escenarios (mítines y otros actos electorales) y discursos políticos programados (ruedas de prensa y declaraciones).

Los medios renunciaron, con ello, a su responsabilidad de trasladar a la esfera pública las preocupaciones de la ciudadanía e incluso a su deber de interpelar a los políticos acerca de los problemas e inquietudes de la sociedad. En definitiva, la cobertura de la campaña electoral realizada por los dos principales periódicos de la Región de 
Murcia no ayudó a estrechar la distancia existente entre los políticos y el público, lo que constituye una de las principales causas del descrédito de las instituciones políticas y del descontento ciudadano.

\section{Referencias bibliográficas}

ARROYO, María Socorro y ARROYAS, Enrique (2012): "La conversación ciudadana en las noticias de campaña. Análisis de los comentarios de los usuarios de periódicos de la Región en sus ediciones digitales", en ZAMORA, Rocío (coord.): $L a$ imagen del candidato electoral en el contexto de la cibercampaña: Las elecciones autonómicas de 2011 en la Región de Murcia. Sevilla, Punto Rojo, pp. 157-177.

BENNET, Leonard W. (1996): "An introduction to journalism norms and representation of politics?". Political Communication, 13, pp. 373-384.

BERROCAL, Salomé y RODRÍGUEZ, Carlos (1998): Análisis básico de la prensa diaria. Manual para aprender a leer periódicos. Madrid, Editorial Universitas.

BURGUET, Francesc (2008): Las trampas de los periodistas. Barcelona, Trípodos.

CASERO, Andrés (2009): "El control político de la información periodística", en Revista Latina de Comunicación Social, 64: http://www.revistalatinacs.org/09/art 129_828_47_ULEPICC_08/Andreu_Casero.html. [fecha de consulta: 3 de septiembre de 2012].

CENTRO DE INVESTIGACIONES SOCIOLÓGICAS (2011): Informe Preelectoral Región de Murcia. Elecciones Autonómicas 2011: http://issuu.com/cemopmurcia/docs/preelectoral_murcia_2011/8. [fecha de consulta: 15 de septiembre de 2012].

CENTRO DE INVESTIGACIONES SOCIOLÓGICAS (2011a): Barómetro de mayo. $\mathrm{N}^{\mathrm{o}}$ 2.888: http://www.cis.es/cis/export/sites/default/-Archivos/Marginales/2880 2899/2888/Es2888.pdf. [fecha de consulta:15 de septiembre de 2012].

CENTRO DE INVESTIGACIONES SOCIOLÓGICAS (2011b): Barómetro de junio. $\mathrm{N}^{\mathrm{o}}$ 2.905: http://www.cis.es/cis/export/sites/default/-Archivos/Marginales/2900 _2919/2905/Es2905.pdf. [fecha de consulta: 15 de septiembre de 2012].

GOMIS, Lorenzo (1991): Teoría del Periodismo. Cómo se forma el presente. Barcelona, Paidós.

KOVACH, Bill y ROSENSTIEL, Tom (2003): Los elementos del periodismo. Madrid, Ediciones El País.

LANDRY, Réjean (1998): "L'analyse de contenu”, en GAUTHIER, Benoît (Ed.): Recherche sociale. De la problemátique à la collecte des données. Sillery, Presses de l’Université du Québec, pp. 329-356.

MAAREK, Philippe J. (1997): Marketing politico y comunicación. Barcelona, Paidós.

McCOMBS, Maxwell E. (2006): Estableciendo la Agenda. Barcelona, Paidós. 
PATTERSON, Thomas E. (1980): The Mass Media Election: How Americans Choose Their President. Nueva York, Praeger.

PÉREZ DÍAZ, Pedro Luis, NOGUERA, José Manuel y GRANDÍO, María del Mar (2012): "El discurso político frente a la conversación ciudadana en la cibercampaña autonómica", en ZAMORA, Rocío (coord.): La imagen del candidato electoral en el contexto de la cibercampaña: Las elecciones autonómicas de 2011 en la Región de Murcia. Sevilla, Punto Rojo, pp. 213-238.

ZAMORA, Rocío (coord.) (2009): El candidato marca: cómo gestionar la imagen del líder político. Madrid, Fragua.

\section{Enrique ARROYAS LANGA}

Profesor adjunto

Universidad Católica San Antonio de Murcia

earroyas@ucam.edu

\section{Pedro Luis PÉREZ DÍAZ}

Becario de investigación de la Fundación Séneca.

Universidad Católica San Antonio de Murcia

plperez@ucam.edu

\section{Celia BERNÁ SICILIA}

Profesora adjunta

Universidad Católica San Antonio de Murcia

cberna@ucam.edu

Universidad Católica San Antonio de Murcia (UCAM)

Facultad de Ciencias Sociales y de la Comunicación

Departamento de Comunicación (Área de Periodismo)

Campus de los Jerónimos, s/n Guadalupe 30107 (Murcia) 